\title{
Mastery Goal Orientation, Social Support dan Student Engagement Siswa Madrasah Aliyah
}

\author{
Digdo Rana Pradhata1, Abdul Muhid ${ }^{1}$ \\ Fakultas Psikologi dan Kesehatan UIN Sunan Ampel Surabaya
}

DOI: http://doi.org/10.29080/jpp.v12i1.488

\begin{abstract}
Disengagement may affect academic achievement, level of boredom, and dropout cases. This research aims to study the correlation between mastery goal orientation, and social support with student engagement among students of MAN Sidoarjo. This quantitative correlational research had three scales in collecting data; mastery goal orientation scale, social support scale, and student engagement scale. Having simple random sampling, subjects in this research were 90 students in grade 11. The results of multiple regression analysis show that mastery goal orientation and social support are correlated with student engagement. Besides, the positive correlation explained that the higher mastery goal orientation and social support students have, the higher the student engagement will be.
\end{abstract}

Keywords : mastery goal orientation, social support, student engagement

\begin{abstract}
Abstrak : Keterlibatan siswa yang rendah di sekolah dapat berdampak pada prestasi belajar, tingkat kebosanan siswa, hingga terjadinya kasus dikeluarkan dari sekolah. Tujuan penelitian ini adalah untuk mengetahui hubungan antara mastery goal orientation, dan social support dengan student engagement pada siswa MAN Sidoarjo. Penelitian kuantitatif korelasional ini menggunakan tiga alat pengumpulan data yaitu skala mastery goal orientation, skala social support, dan skala student engegement. Subjek dalam penelitian ini berjumlah 90 siswa dari total populasi siswa kelas 11 sebanyak 452 siswa melalui teknik menggunakan simple random sampling. Hasil analisis regresi ganda menunjukan mastery goal orientation dan social support secara bersama-sama berhubungan dengan student engagement. Hubungan positif menjelaskan semakin tinggi mastery goal orientation dan social support yang dimiliki siswa, maka akan semakin tinggi pula student engagement yang dirasakan.
\end{abstract}

Kata kunci : mastery goal orientation, social support, student engagement

\section{Pendahuluan}

Student engagement merupakan kondisi dimana siswa merasa terlibat aktif dalam kegiatan belajar di sekolah yang mencakup bentuk perilaku, cara berfikir, dan emosi ketika 
mengikuti berbagai kegiatan di sekolah (Fredricks dkk, 2004). Reeve (2012) menggambarkan student engagement sebagai intensitas tingkah laku, kualitas emosi, dan suatu usaha yang dimunculkan individu untuk terlibat aktif dalam kegiatan pembelajaran di sekolah. Menurut Handelsman dkk, (2005), student engagement adalah keterlibatan siswa dari sisi afeksi, kognisi dan interaksi sosial saat kegiatan atau dalam proses belajar. Utami dan Kusdiyati (2015) menambahkan bahwa student engagement memiliki pengaruh yang sangat besar terhadap prestasi siswa.

Fenomena kebosanan yang melanda di kalangan siswa telah menjadi sebuah karakter di lembaga pendidikan (Furlong, 2014). Hasil penelitian Furlong (2014) menunjukkan sejumlah 66\% siswa mengalami kebosanan di lingkungan sekolah dan 17\% diantaranya merasakan bosan selama berada di dalam ruang kelas. Salah satu penyebab kebosanan di sekolah adalah rendahnya keterlibatan siswa. Dampak dari student diseengagement adalah rendahnya prestasi siswa, meningkatnya rasa kebosanan siswa, dan kasus drop out dari sekolah (Fredricks dkk 2004). Appleton dkk (2008) menyebutkan sejumlah gejala yang menunjukkan student disengagement yaitu sikap kurang baik dalam kelas, tidak memiliki semangat mengikuti kegiatan belajar, mempunyai motivasi yang rendah dalam belajar, dan tidak fokus dalam proses pembelajaran.

Ada tiga aspek student engagement yaitu behavioural engagement, emotional engagement, dan cognitive engagement (Frederick, 2004). Behavioral engagement adalah partisipasi yang dilakukan berupa keterlibatan dalam aktivitas akademik sosial. Emotional engagement yaitu keterlibatan perasaan siswa dalam kegiatan pembelajaran berupa reaksi positif ataupun negative baik pada teman, guru, aktifitas akademik sekolah dan sekolah. Adapun cognitive engagement adalah gabungan dari perhatian dan juga keinginan siswa untuk dapat memahami dan menguasai materi ataupun keterampilan.

Fredrick (2004) menjelaskan bahwa terdapat dua faktor terbentuknya student engagement yaitu faktor eksternal dan faktor internal. Faktor internal dari student engagement yaitu berupa hal-hal yang berkaitan dengan kebutuhan dari siswa seperti kebutuhan otonom, kebutuhan untuk berkompetensi dan juga kebutuhan untuk keterkaitan. Berikutnya faktor eksternal dari student engagement adalah faktor yang berhubungan dengan lingkungan seperti sekolah dan juga kelas. Kualitas sekolah dan sistem pendidikan dapat meningkatkan kompetensi siswa karena kesempatan yang diberikan sekolah dapat membuat siswa terlibat dalam berbagai kegiatan. Selain itu dalam lingkup kelas, support yang didapatkan siswa dari guru yang mengajar, orang tua, temanteman sebaya, dan tipe tugas yang diterima ikut mempengaruhi tingkat keterlibatan siswa.

Gibbs \& Poskitt (2010) menyatakan bahwa goal orientation adalah salah satu hal yang mampu meningkatkan student engagement. Goal orientation menjadi sebuah refleksi standar bagi kesuksesan siswa sehingga menjadi sebuah motivasi bagi siswa untuk mencapai sebuah tujuan. Mastery goal orientation yang tinggi pada siswa berpengaruh terhadap tingkat student engagement siswa (Mahesa \& Gagan, 2013). Siswa yang memiliki tujuan jelas dalam belajar akan terlibat secara personal dan akan lebih terarah dalam proses pembelajarannya.

Menurut Pintrich \& De Groot (2003), goal orientation adalah alasan atau tujuan seseorang untuk mencapai sebuah tujuan sehingga tercipta keyakinan diri. Pintrich \& De Groot (2003) mendefinisikan goal orientation sebagai alasan dari sebuah keterlibatan perilaku untuk mencapai tujuan. Mariyanti (2015) menggambarkan goal orientation sebagai keyakinan untuk mencapai tujuan. Penelitian Nuraeni (2018) melihat hubungan yang positif antara goal orientation dan student engagement dimana aspek mastery avoidance dan mastery approach lebih berpengaruh dibandingkan aspek lainnya.

Menurut Schunk \& Pintrich (2012) mastery goal orientation adalah salah satu dari tipe goal orientation yang lebih fokus pada penguasaan atau pemahaman sesuai standar yang telah dibuat individu tentang pembelajaran, pemahaman, peningkatan wawasan dan peningkatan potensi diri. Siswa yang memiliki mastery goal orientation akan memiliki rasa 
dalam diri untuk menguasai sebuah materi, fokus pada materi dan pembelajaran, memaahami dan menyelesaikan tugas dengan batasan yang telah diciptakan oleh diri sendiri, dan selalu berusaha untuk mendapatkan suatu pemahaman. Schunk \& Pintrich (2012) menyebutkan bahwa ciri-ciri individu dengan mastery goal orientation yang tinggi adalah belajar dengan sungguh-sungguh serta meyakini kesalahan adalah sebuah bagian dari pembelajaran.

Social support juga menjadi salah satu faktor untuk meningkatkan student engagement. Hasil penelitian Groves dkk (2015) menunjukkan bahwa student engagement dapat meningkat dengan adanya guru yang terbuka dengan sering berdiskusi dengan siswa. Social support yang diperoleh dari guru, orang tua, dan teman sebaya dapat berpengaruh terhadap student engagement di sekolah (Garcia-Reid, 2007; Saqinah \& Galugu, 2017). Penelitian Saqinah dan Amriani (2019) juga menunjukkan social support dengan student engagement berhubungan secara langsung.

Cohen (2004) menjelaskan bahwa social support adalah dukungan berupa materi, informasi, dan psikologis dari jaringan sosial. Sarafino (2002) mendefinisikan social support sebagai perasaan nyaman, dihargai, mendapatkan perhatian atau bantuan yang didapatkan dari individu lain. Ada empat aspek social support yaitu emotional support, appreciation support, instrumental support, dan information support. social support dimaknai sebagai dukungan yang didapat dari individu lain berupa perasaan empati, perhatian, kepedulian dan rasa nyaman. Adapun dukungan penghargaan meliputi dukungan berupa penilaian positif atau penghargaan atas apa yang sudah dicapai. Selanjutnya instrumental support adalah bentuk dukungan berupa materi seperti uang atau barang. Support terakhir adalah information support yaitu dukungan berupa pengetahuan, saran, nasehat serta petunjuk dalam menyelesaikan masalah.

Jika masih banyak siswa yang disengaged, maka hal itu menandakan bahwa sekolah belum banyak memberikan peluang bagi pengembangan aspek akademik dan sosial bagi siswa (Appleton dkk, 2008). Selain itu rendahnya student engagement dapat berpengaruh pada prestasi siswa yang menurun bahkan dampak terburuknya adalah sampai terjadinya drop out. Variabel mastery goal orientation dan social support dianggap dapat berpengaruh pada tingkat student engagement siswa di sekolah. Penelitian ini diharapkan dapat memberikan gambaran bagaimana kontribusi kedua variabel tersebut terhadap student engagement. Hasil dari penelitian ini diharapkan dapat dijadikan sebagai dasar untuk meningkatkan student engagement siswa.

\section{Metode Penelitian}

Penelitian ini menggunakan pendekatan kuantitatif korelasional untuk menguji variabel bebas yang dianggap memiliki hubungan dengan variable terikat. Metode survei digunakan untuk mengumpulkan data dengan menyebarkan instrumen kepada partisipan. Penelitian ini dilaksanakan di MAN kota Sidoarjo dengan menggunakan simple random sampling. Ada 90 siswa kelas XI yang dilibatkan dalam penelitian ini. Analisis regresi ganda digunakan untuk menganalisa data penelitian ini dengan menggunakan aplikasi SPSS for windows versi 23.0 .

Alat ukur yang digunakan adalah skala mastery goal orientation (Schunk \& Pintrich, 2012) berjumlah 15 aitem dengan nilai reliabilitas ( $\alpha .936)$. Adapun alat ukur dukungan sosial menggunakan social support scale (Sarafino, 2002) yang terdiri dari 20 aitem dengan nilai reliabilitas ( $\alpha .779$ ). Alat ukur ketiga adalah student engagement scale (Fredricks dkk, 2004) dengan 20 aitem dan memiliki nilai reliabilitas ( $\alpha .905)$. 


\section{Hasil Penelitian}

Analisis deskriptif data dalam penelitian ini mencakup skor empirik dan skor hipotetik. Mean hipotetik diperoleh dari $(20+100): 2=60$ dimana $20 x 1$ untuk nilai terendah dan 20x5 pada nilai tertinggi. Adapun standar deviasi hipotetik dalam penelitian ini adalah (100-20) : $6=13.3$. Perbandingan data empirik dan hipotetik variabel student engagement dapat dilihat pada tabel di bawah ini:

Tabel 1

Perbandingan Data Empiris dan Hipotesis Student engagement

\begin{tabular}{|c|c|c|c|c|c|c|c|c|}
\hline variabel & \multicolumn{3}{|c|}{ Empirik } & SD & \multicolumn{3}{|c|}{ Hipotetik } & SD \\
\hline Student & Min & Max & Mean & 9,518 & Min & Max & Mean & 13,3 \\
\hline engagement & 51 & 100 & 80,46 & & 20 & 100 & 60 & \\
\hline
\end{tabular}

Mengacu pada perbandingan data deskriptif pada tabel 1, dapat dikatakan bahwa nilai mean empirik lebih besar daripada mean hipotetiknya yaitu 80,46>60. Hal itu menjelaskan bahwa student engagement pada subjek penelitian ini lebih tinggi daripada populasi pada umumnya.

Subjek kemudian digolongkan dalam tiga kategorisasi engagement yaitu rendah, sedang dan tinggi. Berdasarkan tabel kategorisasi berikut, mayoritas subjek memiliki student engagement yang sedang.

Tabel 2

Kategorisasi Data Student Engagement

\begin{tabular}{ccccc}
\hline Variabel & Rentang Nilai & Kategori & Jumlah (n) & Presentase \\
\hline \multirow{2}{*}{ Student engagement } & $\mathrm{x}<71$ & Rendah & 10 & $11 \%$ \\
& $71 \leq \mathrm{x}<90$ & Sedang & 64 & $71 \%$ \\
& $\mathrm{x} \geq 91$ & Tinggi & 16 & $18 \%$ \\
& Jumlah & & \\
\hline
\end{tabular}

Hasil analisis data menggunakan regresi berganda menunjukan bahwa mastery goal orientation memiliki koefisien korelasi sebesar 0,754 dengan nilai sig. 0,00>0,005. Nilai itu dapat dinterprtetasikan bahwa terdapat hubungan antara mastery goal orientation dengan student engagement pada siswa di MAN Sidoarjo. Hasil uji hipotesis berikutnya pada variabel social support juga menunjukan hasil koefisien korelasi sebesar 0,441 dengan sig. $0,00>0,05$. Hasil tersebut menjelaskan bahwa terdapat hubungan yang signifikan antara social support dengan student engagement pada siswa di MAN Sidoarjo.

Tabel 3

Hasil Uji Regresi Linier Berganda

\begin{tabular}{cccc}
\hline Variabel & Nilai sig. & Harga Koefisien & Taraf Sig. \\
\hline $\begin{array}{c}\text { Mastery Goal } \\
\text { Orientation }\end{array}$ & 0,00 & 0,754 & 0,05 \\
Social Support & 0,00 & 0,441 & 0,05 \\
\hline
\end{tabular}

Berikutnya adalah nilai R square (koefisien determinasi) sebesar 0,683 yang berarti $68 \%$ variabel student engagement dipengaruhi oleh variabel mastery goal orientation dan social support. Adapun sisanya sebesar 32\% dipengaruhi oleh variabel lain yang tidak diteliti dalam penelitian ini.

Tabel 4

Pengaruh Variabel Prediktor

\begin{tabular}{ccc}
\hline \multicolumn{3}{c}{ Model Summary } \\
\hline $\mathbf{R}$ & $\mathbf{R}$ Square & Adjusted R Square \\
0,827 & 0,683 & 0,676 \\
\hline
\end{tabular}




\section{Pembahasan}

Hasil pengujian statistik menunjukan bahwa ada pengaruh mastery goal orientation dan social support terhadap student engagement. Hal ini membuktikan bahwa mastery goal orientation dan social support merupakan prediktor yang signifikan terhadap terbentuknya student engagement. Menurut Gibbs dan poskitt (2010) goal orientation adalah salah satu hal yang dapat meningkatkan student engagement. Pada penelitian Mahesa dan Gagan (2013) mastery goal orientation merupakan jenis goal orientation yang tingkat pengaruhnya besar dibandingkan jenis goal orientation lainnya. Hal tersebut juga sesuai dengan faktor dari student engagement yang dijelaskan Fredrick (2004) yaitu faktor internal bahwa siswa memiliki kebutuhan untuk berkompeten yang didapatkan dari mastery goal orientation dan juga faktor eksternal berupa social support dari guru, teman dan juga orang tua.

Secara parsial, hasil penelitian ini menunjukan bahwa ada pengaruh yang positif dan signifikan dari mastery goal orientation terhadap student engagement. Semakin tinggi mastery goal orientation yang dimiliki semakin besar kecenderungan individu mengalami student engagement. Temuan penelitian ini mendukung penelitian-penelitian sebelumnya yang menyebutkan mastery goal orientation dan student engagement berhubungan secara signifikan. Seperti hasil penelitian Nuraeni \& Yanuvianti (2018) yang menunjukan bahwa goal orientation memiliki hubungan yang positif dan cukup kuat terhadap student engagement. Pada penelitian tersebut tipe mastery avoidance dan mastery approach merupakan tipe yang memiliki skor tinggi. Dalam penelitian Mahesa \& Gagan (2013) juga menunjukan hasil yang signifikan dan positif antara goal orientation dan student engagement.

Penelitian ini juga menunjukan bahwa social support berpengaruh secara signifikan terhadap student engagement. Social support yang tinggi akan meningkatkan student engagement individu. Temuan dalam penelitian ini mendukung hasil penelitian terdahulu yang menunjukkan hubungan yang signifikan antara social support dengan student engagement. Penelitian Saqinah \& Amriani (2019) menjelaskan terdapat hubungan yang positif signifikan antara social support dengan student engagement. Siswa yang memiliki social support yang tinggi secara nyata juga memiliki tingkat student engagement yang tinggi. Galugu \& Baharuddin (2017) juga menunjukan bahwa ada hubungan positif yang signifikan antara social support dengan student engagement. Gunawan dkk (2018) menjelaskan bahwa peer support memiliki hubungan yang positif dan signifikan dengan student engagement.

Mastery goal orientation yang tinggi berpengaruh pada keterlibatan siswa di sekolah. Hal ini sesuai dengan apa yang dikatakan Gibs dan Poskit (2010) bahwa goal orientation adalah salah satu hal yang penting untuk meningkatkan student engagement. Siswa yang memiliki tingkat student engagement yang tinggi menunjukan keinginan dan dorongan dalam diri selama melaksanakan kegiatan pembelajaran di sekolah (Reyes dkk, 2012). Schunk dkk (2012) juga menyatakan bahwa siswa dengan mastery goal orientation yang tinggi akan fokus pada kegiatan pembelajaran, dapat menguasai tugas, mengembangkan kemampuan baru, meningkatkan kualitas dirinya agar lebih kompeten, dan berusaha agar selalu bias memahami sesuatu. Maka dari itu ketika siswa mempunyai mastery goal orientation yang tinggi maka akan memiliki student engagement yang tinggi pula.

Social support yang tinggi berpengaruh pada student engagement siswa di sekolah. Hal ini sesuai dengan apa yang dikatakan Saqinah dan Amriani (2019) bahwa terdapat hubungan yang positif antara social support dan student engagement. Siswa dengan social support yang tinggi dalam mengikuti proses pembelajaran menjadi percaya diri, semangat, dan juga siap menghadapi tantangan dalam belajar (Clirik, 2015). Social support yang diterima siswa akan membuat mereka memiliki rasa percaya diri, dan semangat yang tinggi 
dalam belajar sehingga keterlibatan dalam pembelajarannya pun di sekolah semakin meningkat. Maka dari itu siswa yang mempunyai social support tinggi akan memiliki student engagement yang tinggi pula.

Data kategorisasi dalam penelitian ini menunjukan mayoritas siswa mempunyai student engagement yang cukup baik. Menurut Fredrick (2004) rendahnya tingkat student engagement atau student disengagement berpengaruh buruk pada hasil akademik siswa. Begitupun dengan sebaliknya tingginya student engagement mempunyai pengaruh yang baik pada prestasi akademik siswa. Tingginya student engagement dapat menghindarkan siswa dari kasus drop out dari sekolah.

\section{Simpulan dan Saran}

Secara simultan ada hubungan positif yang signifikan antara mastery goal orientation dan social support terhadap student engagement. Mastery goal orientation, dan social support merupakan variabel prediktor terbentuknya student engagement pada siswa. Secara Parsial, hasil penelitian ini menunjukan bahwa mastery goal orientation, dan social support yang tinggi akan membuat student engagement siswa juga tinggi. Begitu pula sebaliknya semakin rendah mastery goal orientation dan social support siswa maka semakin rendah pula student engagement yang dimiliki.

Temuan dalam penelitian ini berimplikasi pada pentingnya student engagement pada siswa agar dapat meningkatkan prestasi belajar dan meningkatkan kualitas pembelajaran pada siswa. Oleh karena itu, disarankan pada para guru dan orang-orang yang berada di lingkungan sekolah dapat mendukung dan meningkatkan student eengagement pada siswa. Namun, penelitian ini masih dirasa banyak kekurangan dan keterbatasan baik dari sisi teoritis maupun metodologis. Penelitian selanjutnya dapat mencari faktor prediktor lain yang mempunyai pengaruh terhadap student engagement serta menggunakan sampel dan populasi yang lebih luas lagi.

\section{Daftar Pustaka}

Appleton, J. J., Christenson, S. L., \& Furlong, M. J. (2008). Student engagement with school: Critical conceptual and methodological issues of the construct. Psychology in the Schools, 45(5), 369-386. https://doi.org/10.1002/pits.20303

Clirik, I. (2015) Relationship Between Social Support, Motivation And Science Achievment : Structural Equation Modelling. Anthropologist, 20 (02), 232-242.

Cohen, S. (2004) \& Syme (1985). Issues In The Study and Application of Social

Fredricks, J. A., Blumenfeld, P. C., \& Paris, A. H. (2004). School Engagement: Potential of the Concept, State of the Evidence. Review of Educational Research, 74(1), 59-109. https://doi.org/10.3102/00346543074001059

Furlong, M. J. (2014). Handbook of Positive Psychology in Schools. In Handbook of Positive Psychology in Schools. Routledge. https://doi.org/10.4324/9780203106525

Galugu, N. S., \& Baharuddin. (2017). Hubungan Antara Dukungan Sosial , Motivasi Berprestasi dan Keterlibatan Siswa Di Sekolah. Journal of Islamic Education Management, 3, 53-64.

Garcia-Reid, P. (2007). Examining Social Capital as a Mechanism for Improving School Engagement Among Low Income Hispanic Girls. Youth \& Society, 39(2), 164-181. https://doi.org/10.1177/0044118X07303263

Gibbs, R., \& Poskitt, J. (2010). Student Engagement n The Middle Years Of Schooling (year 710): A literature review. Report to the Ministry of Education. In Ministry of Education,New Zealand: www.educationcounts.govt.nz/publications

Groves, M., Sellars, C., Smith, J., \& Barber, A. (2015). Factors Affecting Student Engagement: A Case Study Examining Two Cohorts of Students Attending a Post-1992 University 
in the United Kingdom. International Journal of Higher Education, 4(2), 27-37. https://doi.org/10.5430/ijhe.v4n2p27

Gunawan, F. A., Dewi, F. I. R., \& Tiatri, S. (2018). HUBUNGAN PEER SUPPORT DENGAN SCHOOL ENGAGEMENT PADA SISWA SD. Jurnal Muara Ilmu Sosial, Humaniora, Dan Seni, 1(2), 55. https://doi.org/10.24912/jmishumsen.v1i2.967

Handelsman, M. M., Briggs, W. L., Sullivan, N., \& Towler, A. (2005). A Measure of College Student Course Engagement. Journal of Educational Research, 98(3), 184-192. https://doi.org/10.3200/JOER.98.3.184-192

Kamtinni, Kartono. (1990). Psikologi Perkembangan Anak. Bandung: CV. Mandar

Mahesa, M. F., \& Gagan, H. T. (2013). Hubungan antara goal orientation dengan student engagement pada siswa Sekolah Masjid Terminal The relationship between goal orientation and student engagement in Masjid Terminal School student. 746.

Mariyanti, S. (2015). Model Goal Orientation Sebagai Efek dari Persepsi Quality Of School Life Serta Implikasinya Terhadap Prestasi Mahasiswa Psikologi Jurnal Psikologi. Jurnal Psikologi, 13(02), 57. www.esaunggul.ac.id

Muhid, A. (2019). Analisis Statistik 5 langkah praktis analisis statistik dengan SPSS for Windows (Second Edt). Zifatama Jawara.

Nuraeni, I., \& Yanuvianti, M. (2018). Prosiding Psikologi Hubungan Goal Orientation dengan Student Engagement pada Siswa Kelas 8A di SMPN 3 Baleendah Relation Of Goal Orientation And Student Engagement In Class 8A Student At SMPN 3 Baleendah. Prosiding Psikologi, 4(1), 262-268.

Pintrich, P. R., \& De Groot, E. V. (2003). A Motivational Science Perspective on the Role of Student Motivation in Learning and Teaching Contexts. Journal of Educational Psychology, 95(4), 667-686. https://doi.org/10.1037/0022-0663.95.4.667

Reevee, J. (2012). A Self -determination Theory Perspective on Student Engagement. Korean Ministry of Educational Psychology, 149-171. DOI: 10.1007./978-1-4614-2018-7_7

Reyes, M. B. (2012). Clasroom emotional climate, Student Engagement, and Academic Achievment. Journal of Educational Psychology, 140:700-712. DOI: $10.1037 / \mathrm{a} 0027268$

Santrock, John, w. (2003). Adolesence: Remaja. Jakarta: Erlangga

Saqinah Galugu, N., \& Amriani. (2019). ACHIEVEMENT MOTIVATION AS MEDIATION OF THE RELATIONSHIP BETWEEN SOCIAL SUPPORT AND STUDENTS ENGAGEMENT. 17(2), 1693-1076.

Sarafino, E. . (2002). Health psychology Biopsychosocial interactions. Wiley \& Sons, New York. - References - Scientific Research Publishing, 4th Edition. https://www.scirp.org/(S(351jmbntvnsjt1aadkposzje))/reference/referencespap ers.aspx?referenceid $=767453$

Schunk, D. H., \& Pintrich, P. R. (2012). Motivasi dalam pendidikan : teori, penelitian, dan aplikasi (Edisi 3, C). Indeks.

Undang - Undang Republik Indonesia No. 20 Tahun 2003 tetang sistem pendidikan nasional (SIDIKNAS). (n.d.).

Utami, A. D., \& Kusdiyati, S. (2015). Prosiding Psikologi Hubungan antara Student Engagement dengan Prestasi Belajar pada Siswa Kelas XI di Pesantren Persatuan Islam No. I Bandung. Prosiding Psikologi, $O(0)$, 88-95. http://karyailmiah.unisba.ac.id/index.php/psikologi/article/view/1006 